\title{
FLAW CHARACTERIZATION IN STRUCTURAL CERAMICS USING SCANNING LASER ACOUSTIC MICROSCOPY
}

\author{
Don J. Roth \\ Structural Integrity Branch \\ NASA Lewis Research Center
}

\begin{abstract}
The ability of scanning laser acoustic microscopy (SLAM) to characterize artificially seeded voids in sintered silicon nitride structural ceramic specimens was investigated. The voids ranged from 20 to $430 \mu \mathrm{m}$ in diameter and were embedded up to $2 \mathrm{~mm}$ beneath the surface of the specimens. Probability of detection was determined as a function of void depth and size. Trigonometric relationships and Airy's diffraction theory were used to obtain predictions of void depth and size from acoustic diffraction patterns produced by the voids. Agreement was observed between actual and predicted void depths. However, predicted void diameters were generally much greater than actual diameters. Precise diameter predictions are difficult to obtain because of measurement uncertainty and the limitations of the 100-MHz SLAM applied to typical ceramic specimens.
\end{abstract}


FLAW CHARACTERIZATION IN STRUCTURAL CERAMICS USING SCANNING LASER ACOUSTIC MICROSCOPY

OBJECTIVE: DETERMINE ABILITY OF SLAM TO CHARACTERIZE (SIZE, DEPTH) INTERNAL FLAWS IN CERAMIC SPECIMENS

EXPERIMENTAL APPROACH: SINTERED SILICON NITRIDE SPECIMENS WITH ARTIFICIALLY SEEDED INTERNAL VOIDS

RESULTS AND CONCLUSION: (1) LARGE MEASUREMENT UNCERTAINTY DUE TO EXPERIMENTAL CONFIGURATION

(2) UNCERTAINTY SEVERELY AFFECTED VOID SIZE PREDICTIONS WHICH DEVIATED MORE THAN 100\% FROM ACTUAL SIZES

(3) REASONABLE AGREEMENT BETWEEN PREDICTED AND ACTUAL VOID DEPTHS 
Experiment Rationale: Relationships between fracture strengths and flaw types, sizes, shapes, and locations are being actively investigated to promote understanding of structural ceramic mechanical behavior. Therefore, it is essential to develop accurate flaw characterization techniques for use on as-fabricated specimens.

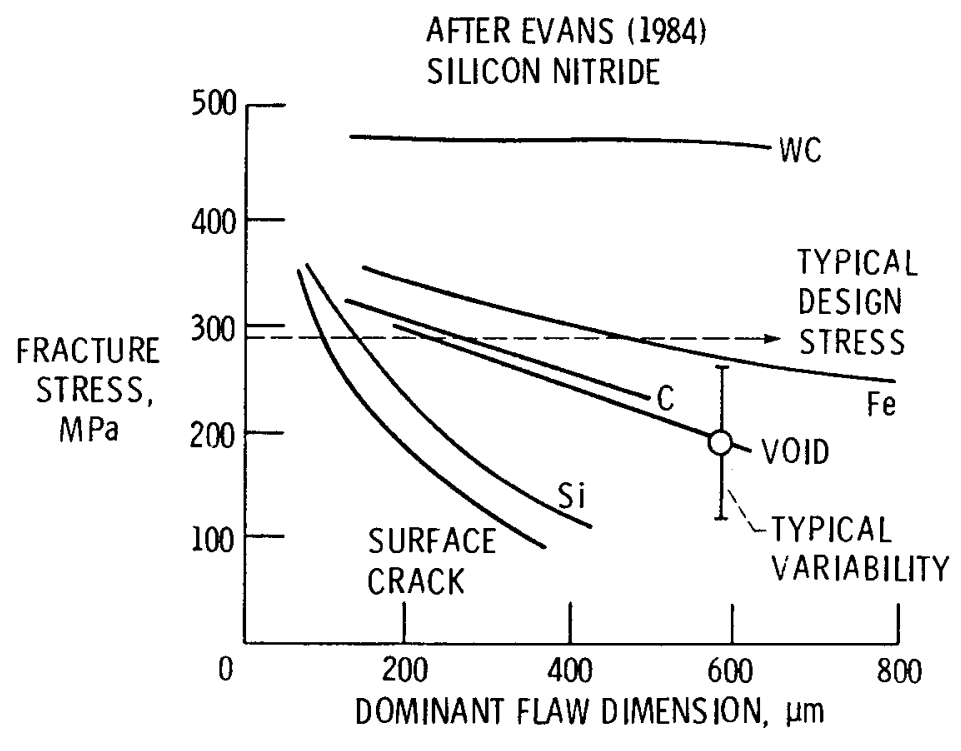

CD-88-32538 
The experimental setup for scanning laser acoustic microscopy of ceramic specimens is shown below.

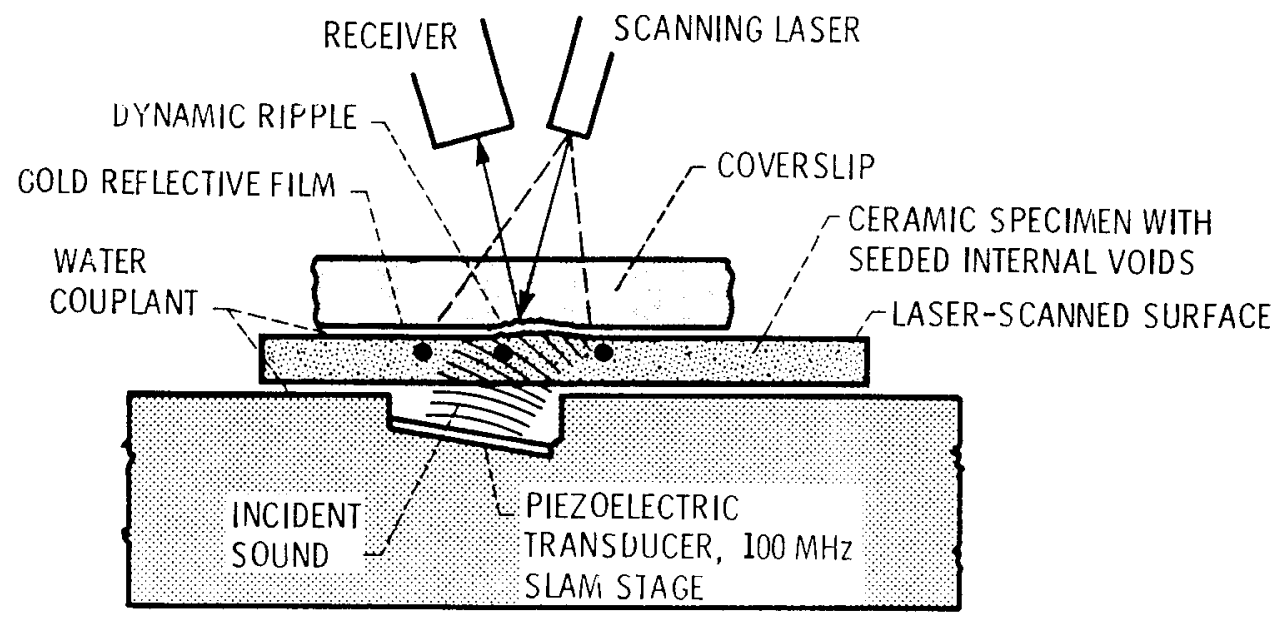

CD-88-32539 


\section{POSTER PRESENTATION}

\section{PURPOSE OF STUDY}

Structural ceramics exhibit wide variability in strength and low fracture toughness because of their brittle nature (Lenoe, 1983; Shannon, 1981; and Salem, 1985). Generally, failure is attributed to discrete flaws such as microcracks, voids, impurities, and oversized grains (Evans, 1984; Heitman, 1983; and Sanders, 1986). The relationships between fracture strengths and flaw types, sizes, shapes, and locations are being actively investigated for structural ceramics as indicated in the figure. Therefore, the ability to accurately characterize existing flaws in these materials by nondestructive evaluation (NDE) techniques has become extremely important.

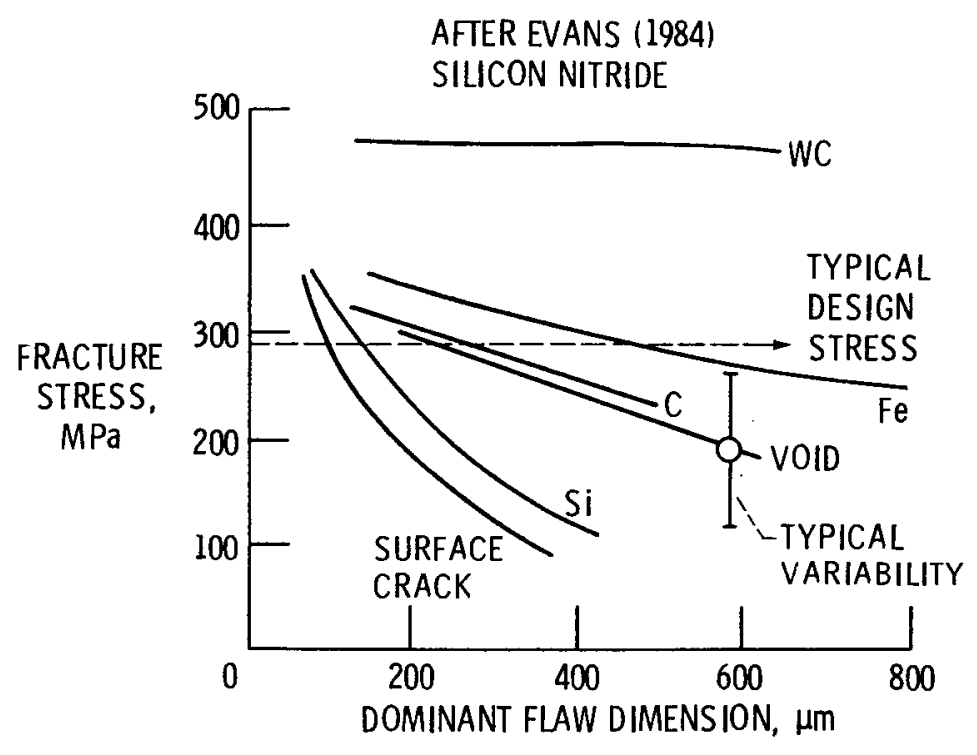

CD-88-32538 
The following is a brief description of the principles of operation of SLAM. Continuous $100-\mathrm{MHz}$ ultrasonic waves traveling through a specimen produce microdistortions on the specimen surface farthest from the transducer. The distortion pattern is determined by the microstructural, bulk, and surface features of the material. A laser beam constantly raster scans a small area of the specimen. The laser beam, angularly modulated by the distortion pattern, is reflected to a photodetector and converted to an electronic signal. In this manner, an "acoustic" image of the specimen, including surface and internal flaws such as voids, inclusions, and cracks, is obtained and displayed on a video monitor in real time at approximately 100x (Roth, 1986a and b; Roth 1987 ; and Generazio, 1986).

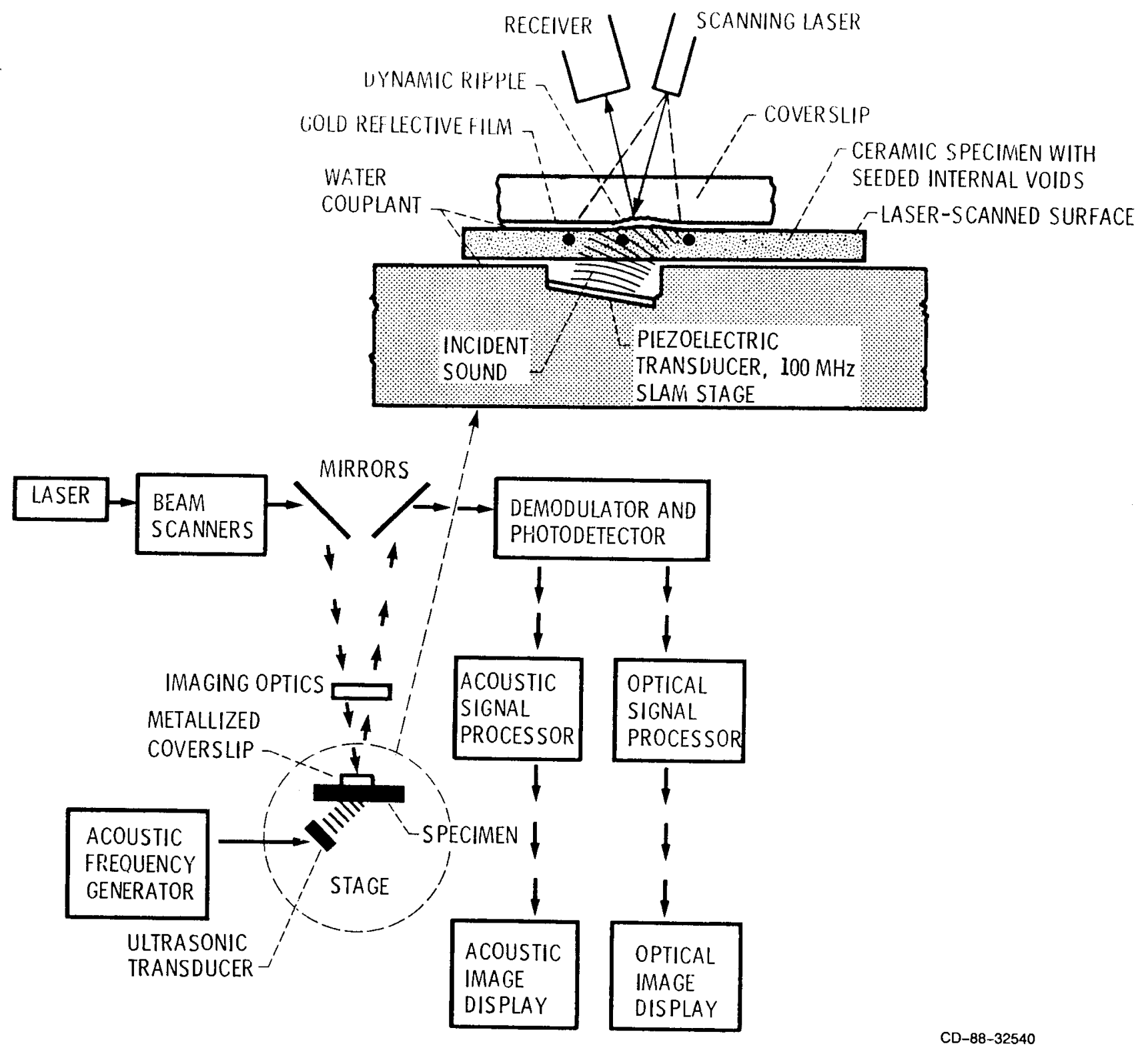


Sintered $\mathrm{Si}_{3} \mathrm{~N}_{4}$ specimens containing seeded internal voids were fabricated by using the processing steps shown in the figure and described in detail by Baaklini (1986). Briefly, plastic microspheres of various sizes were embedded in green specimens and later burned out to create voids within sintered specimens.

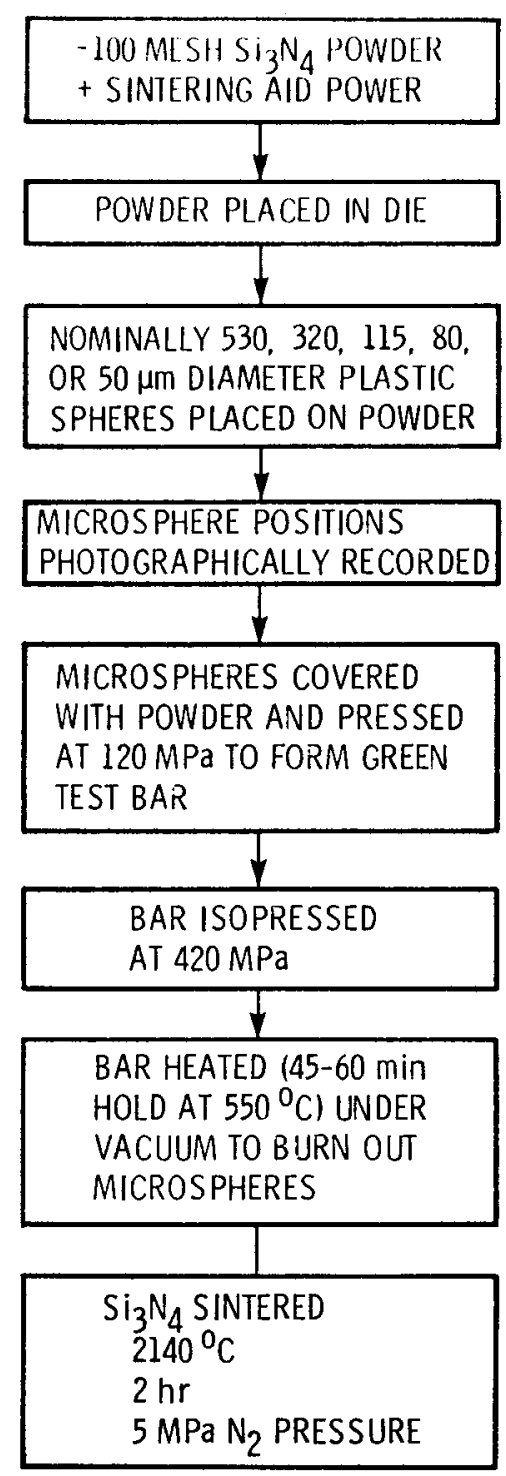


The seven sintered silicon nitride specimens were microstructurally characterized as shown in the table. The 12 internal voids seeded in the specimens ranged from 20 to $430 \mu \mathrm{m}$ in diameter and from 0 to $2 \mathrm{~mm}$ in depth (Roth, 1987).

\section{CHARACTERIZATION OF SPECIMENS}

\begin{tabular}{|c|c|c|c|c|c|c|c|c|c|c|c|c|}
\hline \multirow{2}{*}{\begin{tabular}{|c} 
TEST \\
BAR \\
MATERIAL
\end{tabular}} & \multirow{2}{*}{\begin{tabular}{|c} 
NUMBER \\
OF TEST \\
BARS USED
\end{tabular}} & \multirow{2}{*}{$\begin{array}{c}\text { IENGTH } \\
X \\
\text { WIDTH, } \\
(\mathrm{mm})\end{array}$} & \multirow{2}{*}{$\begin{array}{c}\text { THICKNESS, } \\
(\mathrm{mm})\end{array}$} & \multicolumn{2}{|c|}{ DENSITY } & \multirow{2}{*}{$\begin{array}{c}\text { POROSITY } \\
\text { DISTRIBUTION }\end{array}$} & \multirow{2}{*}{$\begin{array}{c}\text { AVERAGE } \\
\text { GRAIN } \\
\text { SIZE, } \\
(\mu \mathrm{m})\end{array}$} & \multicolumn{2}{|c|}{$\begin{array}{c}\text { PEAK-TO-VALLFY } \\
\text { ROUGHNESS }(\mu \mathrm{m}) \text { OF - }\end{array}$} & \multicolumn{3}{|c|}{ SEEDED INTERNAL VOIDS ${ }^{9}$} \\
\hline & & & & $(\mathrm{g} / \mathrm{ccl})$ & $\begin{array}{c}\% \\
\text { THEORET- } \\
\text { ICAL }\end{array}$ & & & $\begin{array}{l}\text { GROUND } \\
\text { SURFACE }\end{array}$ & $\begin{array}{l}\text { AS-FIRED } \\
\text { SURFACE }\end{array}$ & $\begin{array}{l}\text { TOTAL } \\
\text { NUMBER }\end{array}$ & $\begin{array}{c}\text { DIAMETER. } \\
(\mu \mathrm{m})\end{array}$ & $\begin{array}{c}\text { DEPTH BELOW SPE- } \\
\text { CIMEN SURFACE } \\
(\mathrm{mm})\end{array}$ \\
\hline $\begin{array}{l}\text { SINTERED } \\
\mathrm{SI}_{3} \mathrm{~N}_{4} \\
(S S \mathrm{~S})\end{array}$ & 7 & $30 \times 6$ & $2-4$ & 3.230 & $\sim 100$ & $\begin{array}{l}\text { LESS AT } \\
\text { EDGE THAN } \\
\text { AT CENTER }\end{array}$ & $0.5-1.5^{c}$ & $\begin{array}{l}\text { RELATIVELY } \\
\text { ORDERED } \\
0.5-3.5^{\mathrm{e}}\end{array}$ & $\begin{array}{l}\text { RANDOMLY } \\
\text { ORIENTED } \\
3.0-7.5^{\mathrm{e}}\end{array}$ & 12 & $20-430$ & $0-2$ \\
\hline
\end{tabular}

DOPTICAL PHOTOGRAPH (GROUND SURFACE SHOWN).

DOPTICAL MICROGRAPH OF METALLOGRAPHICALLY POLISHED SECTION (BLACK SPOTS INDICATE POROSITY).

CAVERAGE GRAIN SIZES OBTAINED USING THE HEYN INTERCEPT (MEAN FREE PATHI METHOD GIVEN IN ASTM E112-81.

dTRANSMISSION ELECTRON MICROGRAPH OF REPLICA OF METALLOGRAPHICALLY POLISHED AND ETCHED SECTION

SURFACE PROFILE (USING A $12.5 \mu \mathrm{m}$ DIAMETER DIAMOND STYLUS) (PER PENDICULAR TO GRINDING MARKS FOR SPECIMEN WITH GROUND SURFACE).

OPTICAL MICROGRAPH.

gCHARACTERIZED AFTER SINTERING SPECIMEN AND EXPOSING VOIDS TO SURFACE. 
The seeded internal voids were exposed to the surface by grinding. At this point, the void dimensions were measured optically, and the void depths at the various SLAM inspections were determined (Roth, 1987).
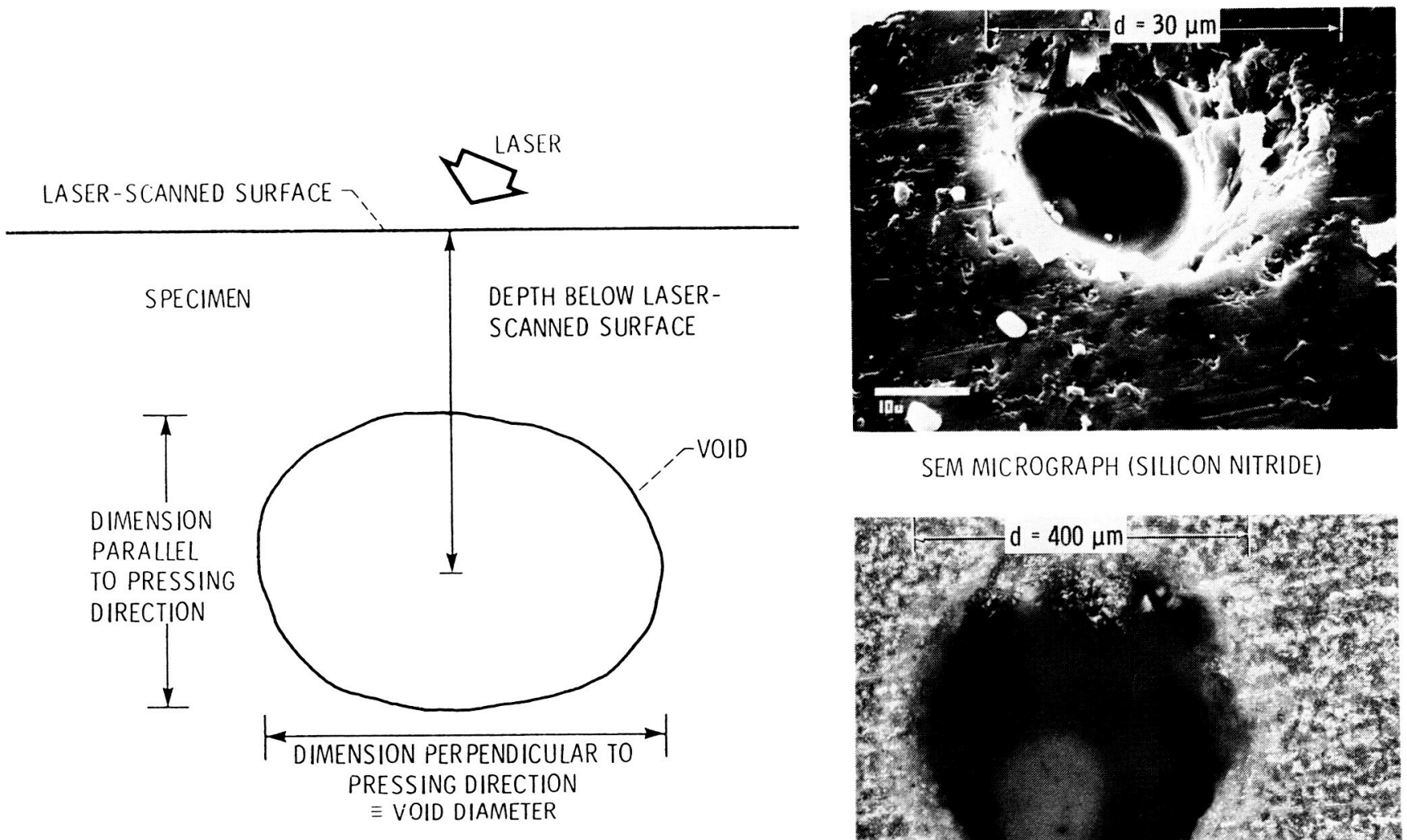

SEM MICROGRAPH (SILICON NITRIDE)

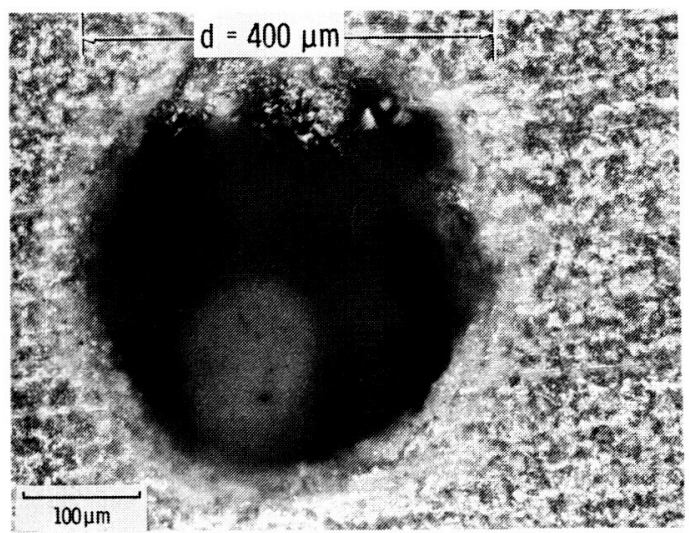

OPTICAL MICROGRAPH (SILICON NITRIOE)

CD $-88-32543$ 
The acoustic image of an internal flaw often consists of a diffraction pattern rather than a facsimile image of the flaw. In this case, it is especially difficult to characterize the flaw. However, techniques have been investigated from which it is theoretically possible to predict flaw shape, size, and depth by using acoustic diffraction patterns (Generazio, 1986; Roth, 1986b and 1987). Measurements obtained from the acoustic images were used to obtain predictions of void diameter and depth (Roth, 1987).
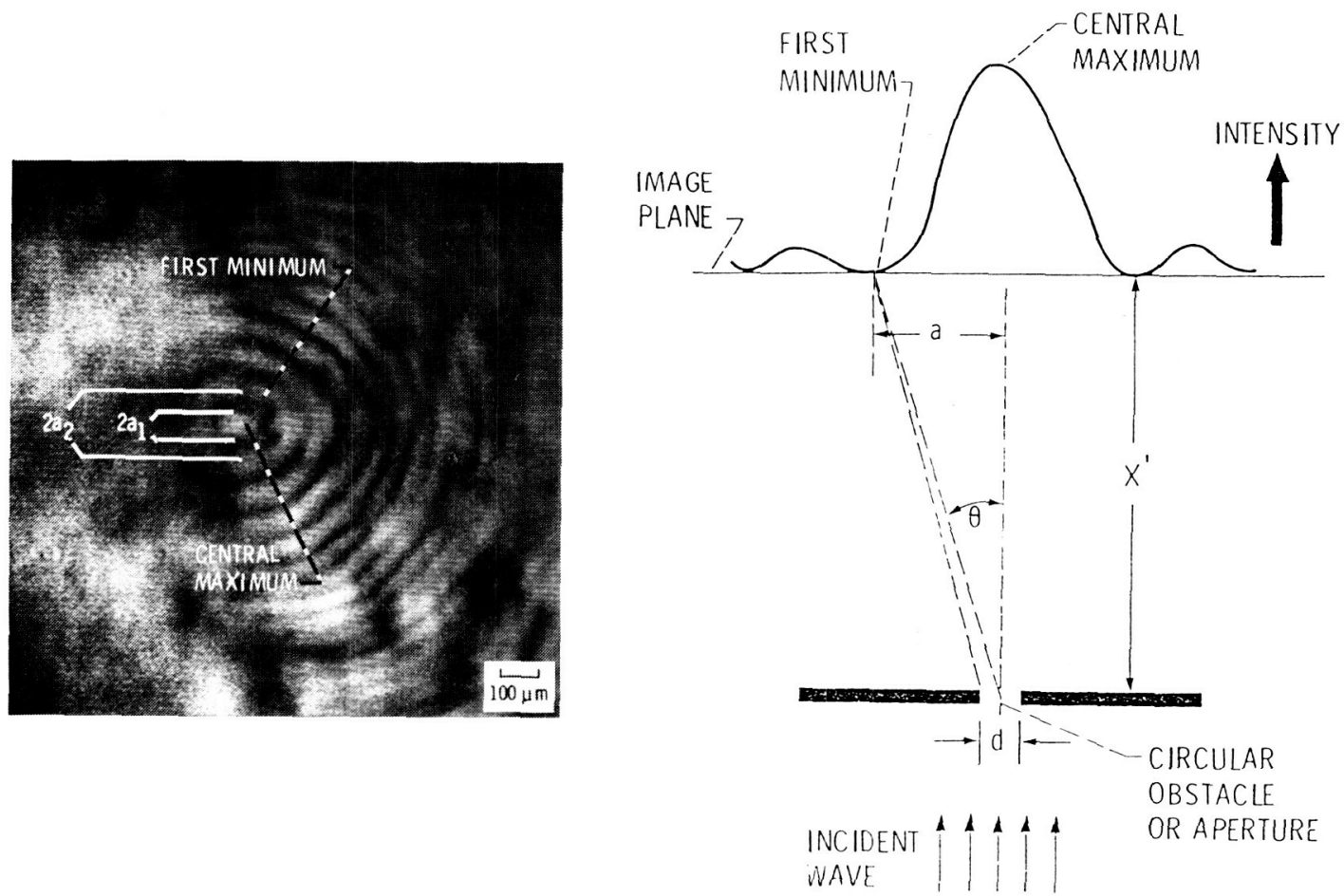
Probability-of-detection data for the seeded internal voids as a function of void diameter and void depth is shown (Roth, 1986b). The range of depths and diameters for which 90 percent or higher probability of detection (at a 95 percent confidence level) was achieved is indicated by the outlined region for sintered silicon nitride specimens (Roth, 1986).

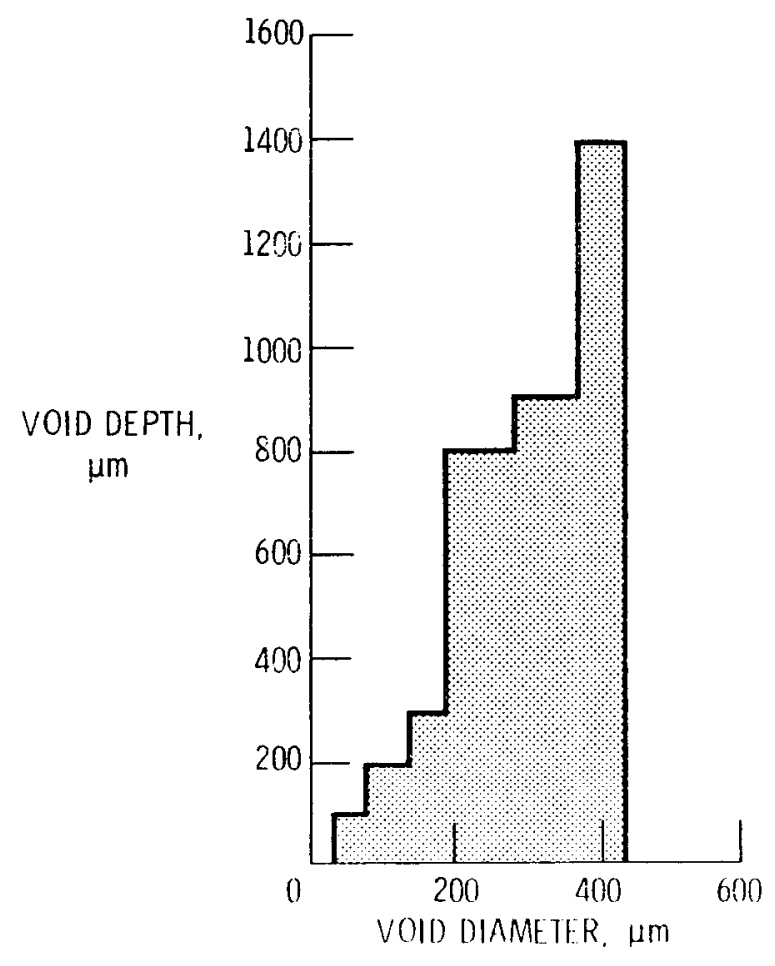


Predictions of depth and diameter were determined for 4 voids at 23 depths. The 23 predicted void depths deviated less than 70 percent from actual depths and 17 were within 20 percent of actual depths. Predicted void diameters deviated more than 100 percent from actual values in all cases but one (Roth, 1987). Examples are shown in the table.

\begin{tabular}{|c|c|c|c|c|}
\hline $\begin{array}{c}\text { ACTUAL VOID } \\
\text { DIAMETER, } \\
\mu \mathrm{m}\end{array}$ & AT & $\begin{array}{c}\text { ACTUAL VOID } \\
\text { DEPTH, } \\
\mu \mathrm{m}\end{array}$ & $\begin{array}{c}\text { PREDICTED } \\
\text { DIAMETER, } \\
\mu \mathrm{m}\end{array}$ & $\begin{array}{c}\text { PREDICTED } \\
\text { DEPTH, } \\
\mu \mathrm{m}\end{array}$ \\
\hline 403 & AT & 1897 & 1113 & 1917 \\
\hline 252 & AT & 568 & 790 & 616 \\
\hline 139 & AT & 197 & 571 & 153 \\
\hline 30 & AT & 79 & 135 & 54 \\
\hline
\end{tabular}




\section{MEASUREMENT UNCERTAINTY}

Measurements obtained from the acoustic images were used to obtain predictions of void diameter and depth. Precise measurements were not possible. Void diameter predictions were more severely affected by the measurement uncertainty than were void depth predictions. Measurement uncertainty was expected to increase with increasing void diameter and decreasing void depth (Roth, 1987).

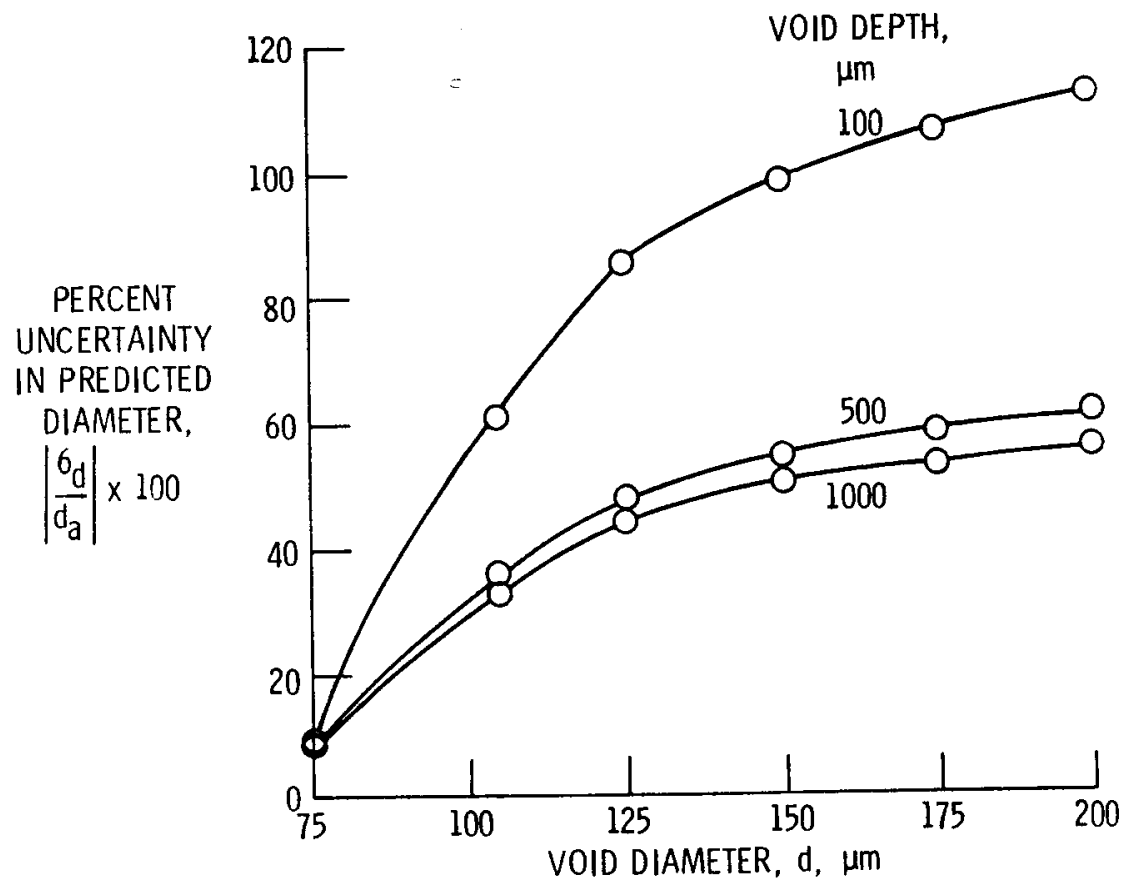

CD- $88-32547$ 


\section{VALIDITY OF RELATION USED TO PREDICT VOID DIAMETER}

The range of void depths and diameters that produced discernible diffraction patterns is shown in the figure below in the area labeled "experimental data region." It is expected that for voids of these diameters and depths, the relation used to predict void diameter is of questionable validity. The relation is most valid for void depths and diameters in the "extreme Fraunhofer region" (far field). Extreme Fraunhofer conditions are difficult to approach with the 100-MHz SLAM configuration applied to typical ceramic specimens (Roth, 1987).

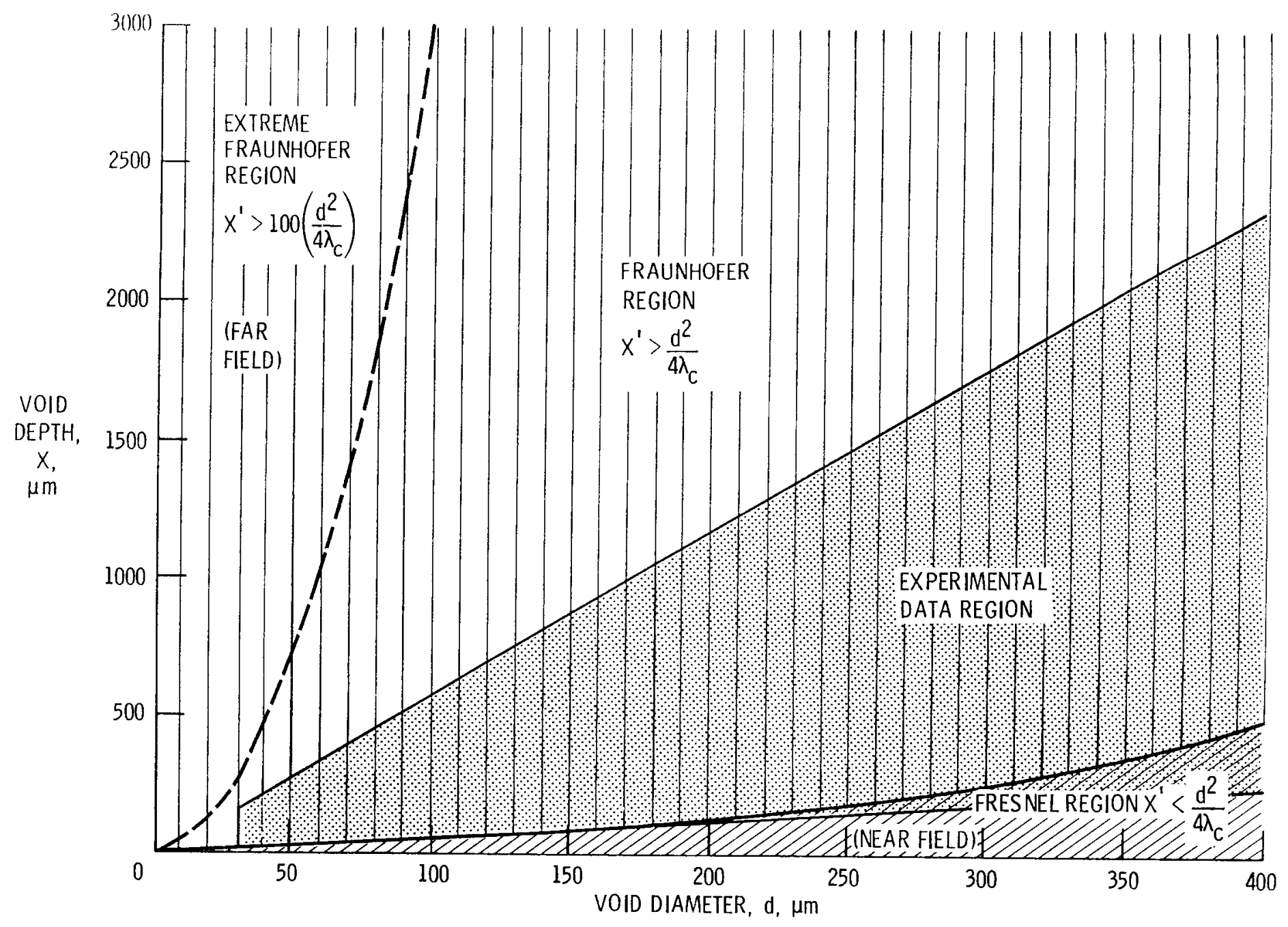


Probability of detection was determined for seeded internal voids in sintered silicon nitride specimens as a function of void size and depth. The acoustic images produced by the voids were used to obtain predictions of void size and depth.

The measurements taken from the acoustic images of the internal voids had large uncertainty associated with them (Roth, 1987). The measurement uncertainty severely affected the prediction of void diameter. Additionally, the relation used to predict void diameter may be of questionable validity for the conditions of this experiment. As a result, predicted void diameters were generally much larger than actual void diameters (Roth, 1987). The measurement uncertainty affected the prediction of void depth less severely. Hence, reasonable agreement was observed between predicted and actual void depths (Roth, 1987). 


\section{REFERENCES}

Baaklini, G.Y. and Roth, D.J., 1986, "Probability of Detection of Internal Voids in Structural Ceramics Using Microfocus Radiography," Journal of Materials Research, Vo1. 1, No. 3, pp. 456-467. Also NASA TM-87164.

Evans, A.G., 1984, "Aspects of the Reliability of Ceramics," Defect Properties and Processing of High-Technology Nonmetallic Materials, Ed. by J.H. Crawford, Jr., Y Chen, and W.A. Sibley, North Holland, New York, pp. 63-80.

Generazio, E.R. and Roth, D.J., 1986, "Quantitative Flaw Characterization with Scanning Laser Acoustic Microscopy," Materials Evaluation, Vo1. 44, No. 7, pp. 863-870.

Heitman, P.W. and Khandelwal, P.K., 1983, "Development and Characterization of Ceramic Turbine Components," Ceramics for High-Performance App1ications III: Reliablity, Ed. by E.M. Lenoe, R.N. Katz, and J.J. Burke, Plenum Press, New York, pp. 645-664.

Lenoe, E.M., 1983, "Recent Accomplishments and Research Needs in Structural Ceramics," Ceramics for High-Performance Applications III: Reliability. Ed. by E.M. Lenoe, R.N. Katz, and J.J. Burke, Plenum Press, New York, pp. 3-18.

Roth, D.J. and Baak1ini, G.Y., 1986b, "Reliability of Scanning Laser Acoustic Microscopy for Detecting Internal Voids in Structural Ceramics," Advanced Ceramic Materials, Vo1. 1, No. 3, pp. 252-258. Also NASA TM-87222.

Roth, D.J.; Klima, S.J.; Kiser, J.D.; and Baaklini, G.Y., 1986a, "Reliability of Void Detection in Structural Ceramics by Use of Scanning Laser Acoustic Microscopy," Material Evaluation, Vo1. 44, No. 6, pp. 762-769.

Roth, D.J.; Generazio, E.R.; and Baaklini, G.Y., 1987, "Quantitative Void Characterization in Structural Ceramics by use of Scanning Laser Acoustic Microscopy, Materials Evaluation, Vol. 45, No. 83, pp. 958-966.

Salem, J.A. and Shannon, J.L., Jr., 1985, "Fracture Toughness of $\mathrm{Si}_{3} \mathrm{~N}_{4}$ Measured with Short Bar Chevron-Notched Specimens," NASA TM-87153.

Sanders, W.A and Baaklini, G.Y., 1986, "Correlation of Processing and Sinterning Variables with the Strength and Radiography of Silicon Nitride," NASA TM-87251.

Shannon, J.L., Jr.; Bubsev, R.T.; Muntz, D.; and Pierce, W.S., 1981, "Fracture Toughness of Brittle Materials Determined with Chevron Notch Specimens." Advances in Ceramic Research (Fracture '81), Ed. by D. Francois, Pergamon, New York, pp. 1127-1144. 